\title{
Troubles and the Family: Changes and Continuities Since 1943
}

\author{
John Welshman \\ History, Lancaster University \\ E-mail: j.welshman@lancaster.ac.uk
}

This article explores continuities and changes in relation to the problem and troubled families' initiatives across three areas: the ways in which families have been defined and described; the nature of the interventions; and the criteria for 'success'. First, while the criteria for identifying troubled families seem initially more explicit than those for problem families, data on the families indicate important continuities. Second, although both initiatives have been characterised by the claimed novelty and distinctiveness of the approaches, it is the practical, commonsense nature of the interventions that have also been highlighted. Third, whereas voluntary organisations and local authorities made little effort to assess 'outcomes' for problem families, or were pessimistic about the chances of success, the troubled families initiative has focused on costs, savings, payment-by-results and families 'turned around'. Overall, troubled families have been much more visible in political rhetoric than their 1950s counterparts.

Keywords: Troubled families, problem families, history, local authorities, continuities.

\section{Introduction}

The topic of 'troubled families' in the United Kingdom has begun to attract some limited attention from academics working in social policy, sociology, psychology, criminal justice and social intervention. Ruth Levitas, for example, has critiqued the 120,000 families figure, tracing its origins to the work done originally for the Social Exclusion Task Force, arguing that the $£ 9$ billion figure for costs is similarly misleading and noting the elision and conflation between 'troubled' and 'troubling' families (Levitas, 2012: 4-12; Spicker, 2013: 50-1). Adam Fletcher, Frances Gardner, Martin McKee and Chris Bonell have noted that the Troubled Families Programme was established after the riots of 2011 and claimed it 'is unlikely to prevent future disorder and may well produce unintended harms' (Fletcher et al., 2012: 2). In work based on two local programmes, Carol Hayden and Craig Jenkins found that behavioural change could be achieved in some families, but that addressing worklessness presented the bigger challenge (Hayden and Jenkins, 2014: 646). The same authors have focused on children taken into care and custody, suggesting that the troubled families agenda was 'a confusing agenda that has involved the mislabelling of a number of interlocking, as well as separate, needs and issues', but was also one that might be subverted by local authorities (Hayden and Jenkins, 2015: 10). Moreover, lan Butler has suggested more generally that the Programme underlines a decisive shift in the nature of the welfare state as it reflects the neo-liberal political project, underscoring a move from 'rehabilitation' to 'rescue' similarly found in a rise in the promotion of adoption (Butler, 2014: 415). 
The best, though not the only, historical antecedent to the troubled families agenda appears to be the problem family discourse of the immediate postwar period. In turn, the history of the concept of the problem family has been approached by historians from a variety of perspectives. One early approach was to see the problem family issue through the lens of the voluntary Pacifist Service Units (PSUs) and Family Service Units (FSUs) that were established in the 1940s (Cohen, 1998). Pat Starkey, for example, argued that the term 'problem family' effectively meant 'problem mother', and that eugenic ideas about the feckless mother determined the ways in which the phenomenon was understood and interventions designed, and contributed to the failure to develop an analysis based more around structural factors (Starkey, 2000a, 2000b, 2002). John Macnicol saw the problem family debates of the 1950s more as a precursor to the underclass debates of the 1980s, tracing the origins of the problem family concept, the family surveys that were carried out, the methodological problems that were integral to them and growing criticisms of the concept from the 1960s. He concluded that while there were continuities in the process of social distancing based on class, gender and age, the 1950s were very different to the 1980s, with virtually full employment for the male workforce (Macnicol, 1999: 93). Drawing on a case study undertaken in Norwich, Becky Taylor and Ben Rogaly explored the kinds of families deemed to be 'unsatisfactory', in terms of economic position, family composition and patterns of behaviour (Taylor and Rogaly, 2007: 452). My own work has been concerned to place the problem family of the 1950s within the broader narrative of the invention and reinvention of the underclass concept in Britain and the United States in the period since 1880 (Welshman, 2013).

Prompted by the high-profile nature of the Troubled Families Programme, academics have more recently begun to trace the parallels between the troubled and problem family agendas in a more systematic manner, building on earlier work that explored discourses of 'support' and 'inclusion' under New Labour, and debates about parenting and responsibility (Gillies, 2005, 2008). Some of this work has focused on the Family Intervention Projects set up by New Labour, particularly those that had a residential element. While researchers in social policy tended to locate the historical antecedents of such polices in similar institutions in the Netherlands and Nazi Germany (Garrett, 2007), my own work traced the history of one such institution, the Brentwood Centre for Mothers and Children (1943-70), established near Stockport, south of Manchester, finding that, while the FSU model was an important influence, the Brentwood regime was much valued by the mothers that were sent there (Welshman, 2008: 522). Sadie Parr has usefully noted continuities between the FSUs and the Family Intervention Projects, arguing that both originated as a result of social anxieties about particular types of families. The overriding concern was 'poor' parenting or mothering, and both the FSUs and the Family Intervention Projects adopted similar methods of working that relied on the personal relationship between workers and clients; the value of practical help was also stressed and casework was conceptualised as innovative and experimental (Parr, 2011: 247). Finally, Jane Read has traced parallels between Sure Start and the Troubled Families Programme, and policy development for under-fives and its implementation in the period 1900-18. She claims that in both time periods symptoms were confused with causes and poverty was seen as a consequence of fecklessness (Read, 2015: 56-7).

The other aspect of this topic that we note here is the focus on comparisons between the problem family debates of the 1940s and 1950s and the troubled family interventions 
since 2011, and the relative silence on the period roughly 1970 to 2006 . After 1970 , one struggles to find much discussion of problem families. Equally, it is only since 2006 that one begins to find mention of problem or troubled families in the more recent discourse. That is not to say that equivalent labels or terms cannot be found. It is well-known, for example, that the 1970s were characterised by a focus on transmitted deprivation or cycles of deprivation. Equally the 1980s witnessed an extensive debate about the underclass, initially in the US, and then subsequently in the UK. Moreover, the years after the election of the New Labour Government in 1997 saw the emergence of a focus on what was termed social exclusion, and the establishment of a Social Exclusion Unit (SEU) in the Cabinet Office. Nevertheless, what is also clear is that each of these existed at a conceptual, academic or policy level and not at an empirical level. The cycle of deprivation was essentially an hypothesis that was tested in an extensive research programme, organised by the then Social Science Research Council and funded by the then Department of Health and Social Security. While the underclass had a few adherents - notably Charles Murray in the US and Frank Field in the UK - most commentators were agnostic and the debate was a narrow one played out in the pages of sociology journals. Finally, social exclusion was above all a concept which was reflected in the early SEU reports but which otherwise had little purchase. Essentially, between roughly 1970 and 2006 there was no targeted programme of intervention with families at the local level that might be deemed equivalent to the problem or troubled variants of such initiatives.

In earlier writing on this topic, I tried to explore four broad themes in relation to the problem family discourse of the 1940s and 1950s and the troubled families initiative since 2011: the policy context, the desire to define and enumerate the families, the emphasis in the rhetoric on intergenerational continuities and the focus on practical help (Welshman, 2014). My argument then was, despite some discontinuities - the policy context and scale of the intervention, for example, are different - that these disguise more fundamental underlying continuities. The way that responsibility for the troubled families initiative has been delegated to local authorities, and the methods employed, indicate striking continuities with the efforts to tackle problem families in the 1950s. Here I would like to look more closely at both continuities and changes across three areas: first, the ways in which such families are defined and described; second, the nature of the intervention; and, third, the criteria for success, whether couched in the language of the 1950s that 'help was withdrawn' or currently that such families have been 'turned around'. Sadie Parr's work was illuminating, but narrow: the historical components were essentially limited to discussion of the FSUs, based on secondary sources, notably the work of Starkey, while the contemporary comparisons were more with Family Intervention Projects than with the broader troubled families agenda; her article was published shortly after the Cameron troubled families speech in 2011. What emerges from my analysis is that while the criteria for success, in particular, are markedly different, there are continuities with the definitions and descriptions of such families, and the nature of the intervention - notably relationships between workers and families.

\section{Definitions and descriptions}

If one goes back to the classic Medical Officer of Health $(\mathrm{MOH})$ articles of the 1940s, it is clear that problem families were perceived to be distinguished by certain features: 
the family was one that had 'not kept pace with social progress', or borrowing from descriptions of feeble-mindedness they were families with 'social defectiveness of such a degree that they require care, supervision and control for their own well-being or for the well-being of others' (Wofinden, 1944: 137). Such a family was large and was characterised by mental deficiency, a squalid home, dirt and disorder, 'irregular' sexual relationships, 'inefficient' mothers and a father who was in a few cases incapacitated by illness but more often was serving in the armed forces or working and earning a decent wage (Wofinden, 1944; Stephens, 1944; Stallybrass, 1946). As Dr R. C. Wofinden, the Acting Deputy $\mathrm{MOH}$, wrote of Rotherham in Yorkshire, 'the children are sent to school unwashed, and dressed in disreputable, dirty clothing and hopelessly inadequate footwear. But such children often have a half-crown clutched tightly in their grubby hands' (Wofinden, 1944: 138).

But as A. F. Philp, the Unit Leader of the Liverpool FSU, and Noel Timms, a Psychiatric Social Worker, noted in 1957, attempts at definition reflected administrative interests the perceived failure of families to improve through contact with the social services, and failure to achieve certain minimum social standards, notably care of children (Philp and Timms, 1957: 5-6). Arguments about definition were rare and the issue was usually avoided by stating that the problem family was 'hard to define but easy to recognise' (Philp and Timms, 1957: 4-7). Thus, descriptions focused on conditions and way of life, child neglect, personal defects - particularly the poor physical health of the problem family mother - and mental deficiency or temperamental instability (Philp and Timms, 1957: 7-20). Dr J. Ardley, the MOH for Blackburn, wrote in 1967, for example, that 'the PROBLEM FAMILY can be likened to an arch in which the keystone is the mother, the bricks are the children and the father occupies a supportive role under the keystone' (Blackburn Health Committee, 1967: 11).

If we fast forward to 2014, troubled families were perceived as families that both had problems and caused problems: truancy and school exclusions, youth crime or antisocial behaviour, parents not working, domestic violence and drug or alcohol abuse (DCLG, 2014a: 7). What is perhaps most striking about the recent discourse is the focus, in addition to the human costs, on the alleged costs to local services and the taxpayer. Thus, to be targeted for help under the Troubled Families Programme, families had to meet three of four criteria: they were involved in youth crime or anti-social behaviour, had children who were regularly truanting or not in school, had an adult on out-ofwork benefits and caused high costs to the taxpayer (DCLG, 2014a: 7). But problems were also perceived as multiple and layered with, on average, nine different problems within each family and with the problems being perceived as both the cause and effect of troubled families' circumstances (DCLG, 2014a: 10). In practice, and in terms of family profiles, the Ecorys UK data published in July 2014, covering 8,447 families or 11 per cent of the families worked with up to that point, suggested that families were slightly larger than average and half were headed by a lone parent. They were perceived as having problems with education, were involved in crime and anti-social behaviour, had domestic violence and parenting difficulties, suffered from health problems and there were high numbers receiving out of work benefits and in social housing (DCLG, 2014a: 9-11, 2014b). Thus, while the language had changed compared to the 1950s - 'data' and 'poor outcomes' for example - it was suggested similarly that inter-connected and overlapping problems indicated the need for swift and effective interventions to help families. 


\section{The nature of the intervention}

In terms of the nature of the intervention, early reports on problem families were uncertain as to exactly what should be done about them, other than to ascertain the size of the problem - 'the number of families in the country living in such deplorable conditions' with suggested policies that included sterilisation of mental defectives and re-orientating the training of health visitors towards the person and the home environment (Wofinden, 1944: 138). Some MOHs used a medical analogy and advocated a policy of prevention and treatment - improving the identification of the mentally defective, training of mothersto-be, marriage guidance, rehousing families and reception hostels and training homes and cottage homes. Dr C. Fraser Brockington, $\mathrm{MOH}$ for the West Riding of Yorkshire, wrote in 1947, for instance, that 'what is required is someone who will take off his (or more probably her) coat and get down to restitution of civilised conditions: thorough cleaning, with a measure of decorating and simple furnishing, followed immediately by practical instruction in housewifery, home-making and parentcraft, and more remotely by prolonged supervision' (Fraser Brockington, 1947: 76).

This reflected the approach that had been pioneered by PSUs during the Second World War and carried on by FSUs. Tom Stephens, General Secretary of the Manchester and District PSU, had written in 1945 that family casework was 'more than the distribution of relief or advice; it is a matter of helping one's neighbours out of difficulties, enabling them to live fuller and more satisfying lives, and guiding them towards the realisation of the best in their lives and in themselves' (Stephens, 1945: 45). Thus, while manual work was one of the distinctive features of the work of the Units, the relief of material needs was one of the least important aspects of rehabilitation. Rehabilitation was 'not so much the restoration of a family to decent standards of material life as the recovery of morale' (Stephens, 1945: 65). Turning to Philp and Timms, they categorised approaches in terms of ascertainment and treatment, noting the role given to the health visitor rested on the assumption that the problem family represented 'a problem of faulty domestic, health and child care standards which can be improved by education and practical example in the home' (Philp and Timms, 1957: 25). By 1957, approaches to dealing with problem families included PSUs, FSUs, casework experiments in New York, special workers both statutory and voluntary - residential training centres and Dutch experiments with segregation (Philp and Timms, 1957: 42-62). Yet Philp and Timms also concluded that little had been done to assess the potential effectiveness of such methods (Philp and Timms, 1957: 63).

With regard to troubled families, much emphasis has been placed on the novelty and distinctiveness of the approach: working with the family rather than viewing them as individuals with problems, using a dedicated worker to target what are perceived as the underlying problems, developing a relationship with the family and drawing in specialist services where necessary. One of the strongest continuities between the problem families and troubled families discourses seems to lie in the focus on the perceived value of practical help. In his troubled families speech, given at Sandwell Christian Centre in Oldbury, in the West Midlands, on 15 December 2011, Prime Minister David Cameron noted that for many of the most troubled families a worker would be appointed, who would agree a plan of action. ${ }^{1}$ In April 2012, Louise Casey, Head of the Troubled Families Unit in the Department for Communities and Local Government (DCLG), said at a conference for local authority staff, 'I want to see people rolling up their sleeves and getting down 
and cleaning floors if that is what needs to be done ... If it takes going round three times a week to get Mum up, then do it' (Bennett, 2012: 21).

In December 2012, it was argued that the five key factors for successful family intervention were a worker dedicated to a family; practical 'hands on' support; a persistent, assertive, and challenging approach; considering the family as a whole, and gathering the intelligence; and common purpose and agreed action (DCLG, 2012a: 6). Local authorities were using three basic models, depending on the needs and problems of the families: family intervention (where workers had caseloads of up to five families), family intervention light (caseloads of five to fifteen families) and family intervention super light. Intervention involved workers and families 'rolling up their sleeves' and 'donning the marigolds', working alongside families, showing them how to clean up and make their homes fit to live in (DCLG, 2012a: 21). Workers thus showed parents how to get their children up in the morning and feed them, and how to prepare meals and how to put them to bed. Day-to-day skills such as cooking, hygiene and daily routines might often have been taken for granted by other agencies, but families might need to learn these things for the first time. Family workers did much of the work 'on the job', showing the family what to do and teaching them basic household skills - often, it was claimed, for the first time - such as shopping and cooking (DCLG, 2012a: 22). A key component of effective family intervention was looking at the family 'from inside out rather than outside in' (DCLG, 2012a: 26). Nevertheless, it is also important to recognise that while it is tempting to seize on Louise Casey soundbites, it is likely there is a disjunction between national discourse and local practice: funding may be used to rebadge existing activities at the local level, including in some local authorities such as Manchester where research has indicated a more structural analysis of troubled families is uppermost (Hastie, 2013).

\section{The criteria for success}

As we have seen, Philp and Timms concluded in 1957 that little had been done to assess the potential effectiveness of methods of working with problem families (Philp and Timms, 1957: 63). Tom Stephens estimated in 1945 that only a tenth of the families encountered by PSUs were capable, with assistance, of rising far above their original low standards of life; the obstacles were 'tremendous' and the help that could be offered 'pitifully inadequate' (Stephens, 1945: 9). Whereas rehabilitation was possible for the Rogers family, it was thought impossible for the Bartons (Stephens, 1945: 9-19). The effectiveness of assistance and social education depended on the manner in which they were employed. Stephens wrote that 'scrubbing a floor, taking a child to school or bringing a parcel of clothes are of small value in themselves; only the insight and imagination of the caseworker can make these insignificant details creative steps to rehabilitation' (Stephens, 1945: 66). Ultimately, it was on 'the interplay of personality, and on the ability of the worker to give from his spiritual resources' that the value of the work would depend (Stephens, 1945: 66). In 1958, Dr J. A. Scott, the MOH for London, estimated that health visitors spent on average twenty minutes a week per 'potential problem family', and twenty-eight minutes per 'hard-core problem family' (Scott, 1958: 207). Otherwise it is difficult to find evidence on individual families and the success or failure of their experiences with workers. A report on twenty-seven problem families in Leicester, in October 1960, who had been provided the free services of home helps, indicated mixed results: in twenty-two families help was to continue, in four it had been withdrawn or the case was closed and in one the family 
was refusing help. A report on one family noted 'after a period of apparent stability, this family has been close to a break-up owing to the mother's liaison with another man. She is now pregnant and is also on probation for stealing. It is recommended that help should continue. $^{2}$

In terms of troubled families, the payment-by-results system has been much more explicit, providing local authorities with an important financial incentive to 'get to grips with and deal with' troubled families. In December 2011, all local authorities were provided with figures indicating the numbers of troubled families in their areas, which represented the families that they were being asked to turn around. The first task was compiling a list of families who would be part of the programme, using the three criteria of crime or anti-social behaviour, education and work, but also offering local authorities a fourth filter for them to add - families that met two of the three criteria and that they were concerned about. They were told the total number of families should match the number indicated in December 2011. The DCLG made up to $£ 4,000$ available for each troubled family that was eligible for the payment-by-results scheme, a proportion paid up-front as an 'attachment fee', and the rest once positive outcomes had been achieved. In March 2012, it was anticipated that local authorities should be able to claim the payments around twelve months after the intervention had started (DCLG, 2012b: 2-8). Furthermore, in May 2014, local authorities were provided with a Troubled Families Cost Savings Calculator (CSC), so that they could undertake a cost-benefit analysis of the programme. They were to cost the kind of problems that troubled families had before and after being part of the programme - covering crime, anti-social behaviour, domestic violence, education, health, housing, child protection, training and employment. The DCLG stated that 'public services are dealing with shrinking budgets and rising pressures, and the CSC can help you demonstrate how working differently with troubled families can make public money stretch further and be a wise investment' (DCLG, 2014c: 4).

\section{Conclusion}

Comparing the problem families discourse of the 1950s and the troubled families initiative of the early twenty-first century, there are both changes and continuities. First, the problem family definitions were in reality descriptions, reflecting administrative priorities, as was noted by Philp and Timms (1957). However, while the criteria for identifying troubled families seem initially more explicit, data on the families that have actually been part of the Programme indicate important continuities. Second, most commentators in the 1950s advocated a policy of identification or ascertainment on the one hand, and treatment on the other. Perhaps uppermost in terms of the latter was the PSU model of practical work, and the local authority emphasis on health visitors and home helps. As with the Units, the troubled family initiative has been characterised by the repeated insistence on the claimed novelty and distinctiveness of the approach. But again the comments of Louise Casey in particular have been to highlight the practical, common sense nature of the intervention (Bennett, 2012). Turning to outcomes and success, this does seem to be more a case of change than continuity. Whereas in the 1940s and 1950s, the PSUs and local authorities either made little effort to assess what would now be called outcomes, or indeed were comparatively pessimistic about the chances of success, the troubled families initiative has been characterised throughout by a focus on costs, savings, payment-byresults and families 'turned around'. In turn, that seems to reflect the much more top-down 
nature of the troubled families initiative: kicked off by the David Cameron speech shortly after the 2011 summer riots, drawing on initiatives on social exclusion pioneered by the previous Labour Government, led by DCLG and implemented at the local level by 152 local authorities against a backdrop of economic recession and a spending deficit. Troubled families are thus much more visible in political rhetoric than their 1950s counterparts.

Alongside the theme of the changes and continuities between the problem family discourse of the 1940s and 1950s, and the problem or troubled families initiatives from 2006, there is still the broader question of what happened in the period in between. By 1970 , the problem family concept had come in for sustained criticism and in the broad field of social welfare had begun to disappear. Equally it was only from 2006 that the language of problem families reappeared, as policy under Prime Minister Tony Blair began to take a more authoritarian and punitive direction, that culminated (under New Labour) in the Respect Agenda and Family Intervention Projects, and continued with the troubled families agenda from 2011 under the Coalition and Conservative Governments. It was not that work with families in poverty did not continue in some form at the local authority or voluntary levels. The research needs to be done - but it seems highly likely that it did. Rather, the discourse around the essentially behavioural emphasis of such ideas operated between 1970 and 2006 at a national, conceptual or theoretical level rather than at a local, empirical or interventionist one. That period saw both Labour and Conservative Governments, periods of economic slump and boom and ideas coming in from outside (particularly the US and France). But it was also a period in which debates about the family were arguably more muted than they had been in the 1950s, or than they were to become from 2006. Such questions about causation and timing are complex and not easy to answer. Overall, while it is helpful to think of such labels as conceptual stepping stones, it seems equally important to look at the gaps between them.

\section{Notes}

1 https://www.gov.uk/government/speeches/troubled-families-speech [accessed 18 April 2016].

2 Record Office for Leicestershire, Leicester and Rutland, Wigston Magna, DE 3277/122, 'Report to General Welfare Sub-Committee, Prevention of Break-Up of Families, Provision of Services Free of Charge', p. 1.

\section{References}

Bennett, R. (2012) 'Local authority officials "should scrub floors": adviser says troubled families need practical help', The Times, 27 April 2012.

Blackburn Health Committee (1967) Annual Report of the Medical Officer of Health, 1966.

Butler, I. (2014) 'New families, new governance and old habits', Journal of Social Welfare and Family Law, $36,4,415-25$.

Cohen, A. (1998) The Revolution in Post-war Family Casework: The Story of Pacifist Service Units and Family Service Units 1940-1959, Lancaster: Centre for North-West Regional Studies.

Department for Communities and Local Government (DCLG) (2012a) Working with Troubled Families: A Guide to the Evidence and Good Practice, London: DCLG.

Department for Communities and Local Government (DCLG) (2012b) The Troubled Families Programme: Financial Framework for the Troubled Families Programme's Payment-by-Results Scheme for Local Authorities, London: DCLG. 
Department for Communities and Local Government (DCLG) (2014a) Understanding Troubled Families, London: DCLG.

Department for Communities and Local Government (DCLG) (2014b) National Evaluation of the Troubled Families Programme: Interim Report Family Monitoring Data, Report by Ecorys UK, London: DCLG.

Department for Communities and Local Government (DCLG) (2014c) Troubled Families Cost Savings Calculator: An Introduction, London: DCLG.

Fletcher, A., Gardner, F., McKee, M. and Bonell, C. (2012) 'The British government's Troubled Families Programme', British Medical Journal, 344, 1-2.

Fraser Brockington, C. (1947) 'Problem families', Medical Officer, 77, 75-7.

Garrett, P. M. (2007) "Sinbin" solutions: the "pioneer" projects for "problem famiies" and the forgetfulness of social policy research', Critical Social Policy, 27, 2, 203-30.

Gillies, V. (2005) 'Meeting parents' needs? Discourses of "support" and "inclusion" in family policy', Critical Social Policy, 25, 1, 70-90.

Gillies, V. (2008) 'Perspectives on parenting responsibility: contextualising values and practices', Journal of Law and Society, 35, 1, 95-112.

Hastie, S. (2013) 'Troubled families: continuities with the past?', Lancaster University BA dissertation.

Hayden, C. and Jenkins, C. (2014) "Troubled Families" Programme in England: "wicked problems" and policy-based evidence', Policy Studies, 35, 6, 631-49.

Hayden, C. and Jenkins, C. (2015) 'Children taken into care and custody and the "troubled families" agenda in England', Child and Family Social Work, 20, 4, 459-69.

Levitas, R. (2012) There May be 'Trouble' Ahead: What we Know about Those 120,000 'Troubled Families', Poverty and Social Exclusion in the UK, Policy Series, Working Paper No. 3, Swindon: ESRC.

Macnicol, J. (1999) 'From "problem family" to "underclass", 1945-95', in R. Lowe and H. Fawcett (eds.), Welfare Policy in Britain: The Road from 1945, London: Macmillan/Institute of Contemporary British History, 69-93.

Parr, S. (2011) 'Intensive family casework with "problem families": past and present', Family Science, 2, 4, 240-9.

Philp, A. F., and Timms, N. (1957) The Problem of 'the Problem Family': A Critical Review of the Literature Concerning the 'Problem Family' and its Treatment, London: Family Service Units.

Read, J. (2015) 'Transformation and regulation: a century of continuity in nursery school and welfare policy rhetoric', Journal of Education Policy, 30, 1, 39-61.

Scott, J. A. (1958) 'Problem families in London', Medical Officer, 100, 83-6.

Spicker, P. (2013) 'Troubled families: what is an "official statistic"?', Radical Statistics, 108, 47-52.

Stallybrass, C. O. (1946) 'Problem families', Medical Officer, 75, 89-92.

Starkey, P. (2000a) 'The feckless mother: women, poverty and social workers in wartime and post-war England', Women's History Review, 9, 3, 539-57.

Starkey, P. (2000b) Families and Social Workers: the Work of Family Service Units 1940-1985, Liverpool: Liverpool University Press.

Starkey, P. (2002) 'Can the piper call the tune? Innovation and experiment with deprived families in Britain, 1940-1980s: the work of Family Service Units', British Journal of Social Work, 32, 573-87.

Stephens, T. C. (1944) 'Sixty-two problem families', Social Welfare, 5, October, 324-9.

Stephens, T. (1945) Problem Families: an Experiment in Social Rehabilitation, London: Pacifist Service Units/Gollancz.

Taylor, B. and Rogaly, B. (2007) "'Mrs Fairly is a dirty, lazy type": unsatisfactory households and the problem of problem families in Norwich 1942-1963', Twentieth Century British History, 18, 4, 429-52.

Welshman, J. (2008) 'Recuperation, rehabilitation, and the residential option: the Brentwood Centre for Mothers and Children', Twentieth Century British History, 19, 4, 502-29.

Welshman, J. (2013) Underclass: a History of the Excluded Since 1880 (2nd edn), London: Bloomsbury.

Welshman, J. (2014) 'Troubled families: change and continuity in intergenerational problematizing', invited plenary address in the 'Families and Relationships' stream at the Annual Conference of the British Sociology Association, Leeds, 23 April.

Wofinden, R. C. (1944) 'Problem families', Public Health, 57, 136-9. 